\title{
Children's literature: reflection of society, culture and ethnic groups
}

\author{
V.W. UDOH \\ Ibrahim Babangida Library, Federal University of Technology, \\ P.M.B 2076, Yola, Adamawa State, Nigeria
}

\begin{abstract}
This paper looks at the working definition of literature in general and gives an overview of children's literature. It also highlights the peculiar problems of Nigerian children's literature, dwelling on the dearth of children's books. This, inevitably, leads to a discussion of foreign literature and its effects on Nigerian children.

Recommendations on how to remedy the current situation are offered, covering the enrichment of the curriculum, encouraging writers, provision and improvement of public and school libraries, parental involvement in the child's development watching out for abnormal behavior in children, and cultivating good habits.
\end{abstract}

\section{Introduction}

Education as a process of learning involves the mental, moral and physical development of a child. A child's education should naturally, begin at home before he attains the age of nursery/primary education. To lay a good foundation for a child's development, proper parental care, training and instructional materials are required. Such parental care, training and materials must have moral and cultural content that can enable the child to become useful to society.

A child's formative years are, therefore, very important. Whatever a child learns within the formative years influences his future. For instance, a child who is induced to cultivate the culture of reading will later seek knowledge. Also, a child who is loved, taught how to love and sees it demonstrated in his home and neighborhood, will grow to love, care, trust and live in harmony with others.

Unfortunately, parents now hardly find time for their children. The economic downturn since the early 1980 s has forced parents into abandoning their homes in search of income for the procurement of basic necessities. Mothers and fathers leave home in the morning and return in the evening, leaving the children with hired help, whose skills at upbringing are doubtful. Instead of guiding the children down sound moral paths, they are exposed to all sorts of influences that negatively affect them.

Those basic societal norms and behaviors that should have been inculcated during the formative years are not only lost but replaced by antisocial behavior, thereby impairing the child's proper development.

Education for All: Culture, Reading and Information, IASL, 1998 
According to the United Nations Declaration of the Right of Children (1979), every child has a right to education.

"The child is entitled to receive education which shall be free and compulsory at least in the elementary stage. He should be given an education which will promote his general culture and enable him on the basis of equal opportunity to develop his abilities, his individual judgment and his sense of social and moral responsibility and be a useful member of his society."

Books are the major tools for achieving these objectives. Children throughout the world grow to understand themselves better through reading.

This paper, therefore, looks at the working definitions of literature and gives an overview of children's literature. It also highlights the peculiar problems of Nigerian children's literature, dwelling on the dearth of children's books. This leads inevitably invariably to a discussion of foreign literature and its effects on Nigerian children. Recommendations on how to remedy the current situation are offered, covering the enrichment of the curriculum, encouraging writers, provision and improvement of public and school libraries, parental involvement in the child's development and watching out for abnormal behavior in children, and cultivating good habits.

\section{Children's literature: a definition}

Children's Literature is a medium of enrichment and socialization through which values are transmitted to the young. According to Compton's Encyclopedia, literature is more than language.

"It is ideas and feelings set to the music of language and it takes the form of words and pictures put together with imagination. Literature is a way of seeing, a way of feeling and a way of knowing."

A listener or reader sees through the eyes of others, he feels their feelings, thinks their thoughts, dreams their dreams. In that way he escapes from the confines of his own time and place as well as the narrowness of himself.

According to the Bloomsbury Dictionary, Literature is "Composition in verse or prose, especially those of fine quality." This also include folklore, picture books, romance, science fiction, people and classics.

Children's literature provides the intellectual corpus by which a child is first introduced to the philosophy, social and cultural norms, values, aspirations and hopes of his society. It provides the avenue for language skills development, knowledge acquisition, social and functional education. Andree Michael asserts that "literature written for children and teenagers is one of the most effective means of communicating standards, values and ideologies" (p.20).

Through literature, a child also learns to understand and appreciate his culture and that of others, his own ethnic group and the various ethnic groups within his environment thus promoting tolerant behaviors among children from different backgrounds.

In traditional African homes, children were/are treated to a wide range of stories that touch on moral values, culture, myths, ethnic groups, valor, hard work, and so on. Examples 
include fourteen hundred cowries: traditional tales of Yorubas by Abayomi Fuja, and the Newcomer and other stories by Khiddu Makubuya, which is a collection of stories explaining the origin of things as well as interpersonal relationships and good neighborliness. Such stories did, and where they are still in practice, still do, help in no small measure to pattern young people's behavior.

For example, if a child is taught early to adopt good behavior and made to understand the repercussions of anti-social behavior, he will lead a disciplined life. Such moral lessons will help him become a good citizen and appreciate the rights and lives of others. He will understand that though his culture and ethnicity may be different, he is neither superior nor inferior to others. This awareness, no doubt, will make him more humane and tolerant.

Children also learn about their country, their past and present leaders, their stake and duties in their society. Also, the virtues of hard work and the need to be productive for their own benefit and that of society are emphasized. These elements and awareness determine which direction the child will take. A responsive society or nation breeds responsible and patriotic citizenry.

\section{The dearth of relevant children's literature}

Major methods of imparting knowledge are through oral and written literature. Children depend on what they are told and what they read for their mental and social development. Despite our rich cultural heritage, it is lamentable that there is very little children's literature. Nigerian writers and publishers, for various reasons, do not consider children's literature a viable enterprise. Lack of patronage has been cited as one of the reasons writers shy away from children's literature. Although some writers bemoan their inability to get the authorities to recommend their publications for use in the schools, the authorities cite low quality and high cost as their reasons for not patronizing these authors.

Some potential authors are unable to write because they lack the necessary funds to embark on such projects. Research/publication grants are now in short supply. Those who are able to generate material rarely find publishers for their work.

Publishing, some publishers would say, is business and for it to be worth their while, the returns must be attractive. This consideration influences their decisions on what to accept for publication. With the escalating cost of printing materials, publishers are wary of taking risks. The dearth of books, therefore, has robbed young people of the opportunity to gain extensive knowledge of the diverse cultural and ethnic groupings in Nigeria and in Africa in general. There is no doubt that the exposure of a child to quality literature would help in developing the social conscience of the child. The paucity of children's literature is therefore a great loss to the young people, the nation and Africa as a whole.

In most nursery and primary schools in Nigeria, oral literature is being taught. It is true that through listening to stories, a child learns how to speak and obtains information on his environment. Oral literature, helps in developing a child's audio-visual perception, distinction and memory; books, however, help him to learn better. The impact of written literature or books is greater, since they form part of the child's library for future reference.

Children's literature, is a mirror in which the child sees the various images of the society, its diverse culture and different ethnic groups. Children's literature should portray the good 
aspects of the society, show the ills that must be dispensed with and give hope to the reader. Societal complexities must be thoroughly explained so that the child does not perceive it incorrectly. Children, especially in the formative years, are highly impressionable. If a child pictures a society that is just and fair, where wrong is punished, he will grow to become a good citizen.

Through literature, a child understands the culture of other ethnic groups and tries to appreciate and respect them. This enables him to socialize without inhibition, to accept and be accepted by other ethnic groups. Children's literature must not be restrictive. It must touch on every aspect of life, taking into consideration the age of the reader. A child will want to know how many ethnic groups there are in Nigeria, a brief history of each ethnic group and its cultural affinity. He will want to know what the 'dos' and 'don'ts' are, and their justification. Children are naturally inquisitive and should be guided toward acquiring useful knowledge.

In summary, the procurement and distribution of children's literature are beset by the following problems, a situation similar to that of India and other developing countries as observed by Panandiker (1992).

1. the large size of the country limits distribution of what is available.

2. the large population of children, many of whom cannot read and write, plus high rate of dropouts due to poverty.

3. Low per capital income, with families unable to buy books for their children.

4. The attitude of parents who pay little attention to the need for good books.

5. The lack of good public and school libraries.

6. The multiplicity of languages, very few of which are written. In addition, patronage for these publications in these languages is minimal, as the official language is still English. This began to change in the late 80 s with the introduction of instruction in the mother tongue.

7. The lack of locally supplied newsprint. This affects the quality of production as well as the cost. They are hesitant to publish either because local authors are not enthusiastic or because the books are not patronized. The books which sell more are common entiance and aptitude tests.

8. Strong foreign competition, regardless of the unfamiliarity of foreign books.

9. The government's earlier unwillingness to favor ind igenous publishers. Fortunately, evaluation exercises of library books including supplementary readers under the auspices of the National Primary Education Commission (NPEC), now allows Nigerian publishers and authors to compete.

10. Television and video recorders, which have constituted a threat to reading as children spend hours glued to the television and or watching video films. This has not yet reached alarming proportions but the threat is real.

11. Books on Nigeria written by non-Nigerians give an erroneous picture of Nigeria and Nigerians. Indigenous writers and publishers, in my view, would do a better job.

\section{Foreign literature}

Literature is a bridge that connects various peoples of the world and attempts to homogenize them. Through exposure to a range of literature, a child learns about various races, languages, cultures, ethnic groups, geographical locations, social settings and values. 
This knowledge enables him to see other people the way he sees himself, identifies socio-cultural similarities, and helps in understanding differences where they exist.

Over $70 \%$ of the literature presently in use in nursery/primary and secondary schools in Nigeria is foreign. The influx of foreign literature has no doubt helped greatly to fill the void created by the inability of our local writers to meet the ever-increasing demands for books. No nation can advance economically, socially and technologically without quality education and to achieve this, qualitative books must be procured and made available to the reading populace. Children tend to be anxious and hyperactive. They have high levels of energy that should be directed toward total development which only education can guarantee. By inculcating the culture of reading and providing exciting but sound cultural and moral content in literature, children can be spared moral bankruptcy and social problems that afflict youth all over the world. A busy child, properly guided, will find no attraction in destructive activities. After all, it is said that an idle mind is the devil's workshop.

Foreign literature therefore, not only engages the child but enables him see and feel the world. His personality is molded by what he learns and by the impression he gathers.

\section{The effect of foreign literature}

As much as foreign literature is necessary for the mental development of the African child and the Nigerian child in particular, it does not represent the content of our rich cultural and national values. Nigeria is a fascinating country with vibrant cultures, lively and close-knit ethnic groups with very strong family ties who have a firm belief in eternal values of love, peace and friendship in spite of Nigeria's diverse culture, ethnicity, dialects, religion, population and socio-economic/political differences, which make it a very unique nation. There may be vast differences that ordinarily would have torn the country apart, but resilience and a firm belief in one polity have worked to keep the various groups together.

But none of the foreign children's books present this picture of Nigeria. The children who are the direct consumers of these books go through school learning little or nothing about their own country and its people. A Nigerian child who has not traveled beyond his immediate environment can tell you much about Europe and America but is oblivious of the events around him. A Nigerian child is likely to know about the 1861-1865 American Civil War or the French Revolution but not the Nigerian thirty-month civil war which ended in 1970.

The unrestricted exposure of Nigerian children to foreign literature and materials has made them more Western/American than the Nigerian children they are supposed to be in terms of language, attitude, taste and orientation. The main language of communication in many Nigerian homes, especially the elite class, is English. Nigerian dialects are fast becoming secondary, if they are spoken at all. Even then, American English is preferred to Queen'ss English among the young people and the two are confused.

Children's mannerisms are changing daily. The ways in which they talk, walk, gesticulate, dance, stand or even sit reflect what they see in pictures and films or what they read. It is rude for a child to put his hands in his pockets while talking with or taking instructions from elders, or even to speak without being addressed. In most parts of Nigeria, children were 
required to kneel or prostrate themselves while greeting their parents or elders. Children were required to stand or bow when an elder entered a place and would remain so until asked to stand or sit. It is against our tradition for a child to sit while his parents receive visitors or be seen within the vicinity unless invited.

Today, children do the opposite and even go to the extent of scolding their parents or elders as if they were equals. This behavior may not be frowned at in Europe, North America and perhaps other countries of the world, but here in Africa, especially Nigeria, it is not only unbecoming but abnormal.

The Western and American yen or should one say romanticism, has cut deep into our Nigerian society so that Nigerian children hardly care about what is African. Children now sport unusual clothing and hairstyles with strange inscriptions. They no longer find our native dress and hairstyles attractive. They give up their native names in favor of the names of characters they have read or watched in the movies.

Nigeria's culinary culture, one of the richest in the world, is also in danger. These foods are highly nutritious, natural and promote good health and longevity. In Eastern Nigeria, breakfast was something everybody looked forward to. Yam pepper-soup was the favorite, prepared with lots of fish, spices and herbs. This is good for the stomach and it fights cold and other ailments depending on the choice of spices and herbs. Western and northern Nigeria also have very rich delicacies that are nourishing and healthy.

Today, children favor Rice Crispies, corn flakes, oats, sweets and other dishes that are once alien to us. This acquired taste has to a great extent discouraged the promotion of our own culinary culture and has affected the production of staples. Our local beverages are no longer appealing to our young people. The children of the elite are more affected by this trend. In one case man fell out of favor and lost all he had. Government patronage which had provided him with income, had ended and he knew that if he had to live, he and his family had to adjust. Although he and his wife were ready to eat their local food, the children could not be persuaded to take Kunu for breakfast and Tuwon dawa ${ }^{2}$ for lunch and dinner. The foreign meals they were used to were beyond his means and therefore his children would eventually be persuaded by hunger to try their traditional dishes.

Also, children no longer find small gathering, where elders would usually thrill them with African folktales that teach African values and culture attractive. Instead, they now prefer staying home and watch foreign children's programs and even adult films which teach alien values and cultures. The result is that our children now suffer from what I will call and identity crisis, growing up oblivious of their roots.

Along these lines, one some of the respondents interviewed said:

I feel in the world of today the issue of foreign culture in our literature will be difficult to define because the world today has become a [global] village with information running all over, equipment and gadgets have become highly sophisticated so that their usage has become highly competitive. This is reflected in

1 Kunu is a local soft drink/pop made out of guinea corn and maize millet kunu gyada, which is a native porridge made out of grains with groundnut.

2 Tuwon dawa massara paste is a native semolina made into a hard paste; gero is eaten with a variety of local soups. 
our literature, more so now that urbanization has increased tremendously. Children now have access to whatever is considered "the latest"; for this reason, the literature must contain what is modern and would have to interest them.

\section{Government efforts to promote and preserve our cultural heritage}

The federal government, under the federal Ministry of Information and Culture has in place structures that are aimed at promoting cultural activities in all the thirty-six states of the Federation, including the Capital Territory. At the state level also, there are cultural centers under the relevant ministries. Cultural fairs are organized annually by federating states to show-case their cultural heritage. Such fairs are educational as they provide children with the opportunity to learn about the various ethnic groups in Nigeria and their cultures. The National Museum houses important artifacts from various ethnic groups in Nigeria and national delicacies are served to visiting public. School children are supposed to be part of this visiting public, but how many such excursions to places of national importance are arranged by schools or parents for children? Have the various cultural fairs and efforts of the government done much to persuade Nigerian children to be Nigerians and take pride in their cultural heritage?

The various efforts of government are not making the desired impact because parents and teachers have been unable to arouse children's interest in that direction. Children have to be taught, shown around and provided with materials that should be presented in such a way that children will find exciting. But with the westernized behaviors of parents and teachers it is unlikely that children would develop interest in the local culture which their parents are not accustomed to.

\section{Recommendations}

The following recommendations, if adopted, would go a long way toward addressing some of the problems discussed in this paper.

\section{Enrichment of school curriculum}

School curriculum has to be expanded to allow for more demonstration and teaching of our culture, national values, and the history of Nigeria and the African continent. For this policy to work, teachers or prospective teachers have to be trained or retrained in the relevant areas and appropriate incentives given to encourage them. Nigerian culture should be made one of the core subjects, and children who excel should be rewarded.

\section{Encouraging writers}

The paucity of local writers and the inability of existing domestic and local literature to satisfy our local needs, calls for government intervention as most writers cannot afford the cost and lack the encouragement to write for children. To encourage writers to enter this difficult terrain, the government should establish a Children's Literature Fund with the clearly defined objective of enabling gifted and trained writers could draw funds for their projects. When published, that is after passing quality test, the books should be made available to pupils at highly subsidized prices, much lower than the comparatively less expensive foreign books. 
Nigeria is a nation with over 250 ethnic groups and about 350 dialects. Writers should also be encouraged to write in other languages other than the three main languages - Yoruba, Igbo and Hausa. Publications in as many languages as possible would help in the promotion and understanding of our local languages. Income from the publications should be attractive and sufficient to sustain writers; otherwise, writers' interest will wane or be diverted to other areas considered more profitable.

\section{The provision/improvement of public and school libraries}

The population of school-age children is increasing annually and over $75 \%$ of these have parents within the low-income bracket. The pressure on their income is so much that they cannot afford their children's books. The government would be assisting greatly if well-stocked public libraries were provided at strategic locations to service the various strata. Reading improves a people and helps in the building of a united, peaceful, caring and progressive society. For a society to attain greatness its people must be enlightened and positive enlightenment can only come through well-structured education. The tools needed therefore are books which are presently beyond the reach of most children. The alternative, then, is functional public and school libraries, where children, especially from poor homes can access books and other learning materials. When they are positively engaged, such children will be kept off the streets and away from destructive habits or activities.

\section{The role of parental input in the child's development}

Much has already been said in this paper about the expected role of parents in a child's development. There are, however, other basic contributions expected of any parent to a child's proper mental, emotional, cultural and psychological development. As already stated, a child's education begins at home but should not stop when he is enrolled in school. Parents should continue to teach and evaluate the progress of their child at all times and ensure that proper training materials are procured. Children like to copy or do what they are told to do. Parents should be wary of saying or doing things that will negatively affect the child.

\section{Watching out for abnormal behavior}

School is a place where people from different backgrounds congregate for the purpose of learning. While in school, children are exposed to all types of habits and mannerisms. It is the responsibility of parents to watch their children and correct any abnormal behavior before it gets out of hand.

\section{Cultivating good habits}

A child's attitude is greatly influenced by his background. Parents who are time-conscious and see to it that their child gets to school on time are teaching the child to be punctual and the child will grow up to be a respecter of time. Equally, a child who is taught to respect elders grows up with that attitude. These are some of the necessary contributions expected of parents, without which the child would not only will be anti-social but will not realize his full potential. Children are tomorrow's leaders and a disciplined child today results in a disciplined society tomorrow. 


\section{Conclusions}

Children are the seeds of any nation. For the seeds to germinate and blossom, they must be planted on fertile soil and nurtured. Therefore, the development of a child depends on the materials he is provided and to a great extent, his environment. A child takes his first

instructions from his parents and before he attains school age he draws lessons from his environment. The nursery/primary school is, therefore, a continuum of his mental and social development. The responsibility for a child's development resides primarily with his parents; the roles of society and school are only complementary.

The process of reorientation aimed at cultural rejuvenation must start with parents/adults who are, as expected, role models for the children. A culturally bankrupt parent cannot offer a child what he himself lacks. They must, first, learn about our culture and national values so that the children can be exposed to these early. For those who live in the cities, occasional visits to their natural homes (villages) should be encouraged to enable children to see, feel and learn about their roots. That would make a better impression than stories told or written.

The local school, in addition to the home, is another setting for learning and socialization. For children to develop socially and culturally, the teaching staff must consist of people knowledgeable in the subjects which touch on our national values and culture. Children's education is very important and must not be left in the hands of young inexperienced teachers.

The instruction and instructional materials on Nigerian history and cultural heritage available to children in our local schools are scant and cannot have the desired impact. For Nigerian children to love and appreciate their culture and country, efforts should be made to educate them on these issues. A situation where a Nigerian child wants to be an American, Briton or a citizen of another country besides his own, shows obvious lapses in his upbringing and constitutes a serious indictment of the parents and society in general.

Every nation has a set of values, cultures, systems, and so on that are peculiar to its people and which it must preserve in order not to lose its identity. No nation is static. In fact, science and technology are progressively homogenizing the world so that diverse cultures, values and systems are now thrown together, each trying to influence the other. What this should do for any nation is to enable it to improve its existing systems and not to abandon them for another.

Finally, my position here is not against foreign literature. In fact, it has helped to bring children of the world closer together. As an educator, I endorse the exchange of children's literature among countries and peoples as it encourage cross-fertilization of ideas, sharpens a child's intellect and promote cultural, ethnic and racial harmony. The literature I endorse is that which positively affects the child, enables him to retain his identity and protects him from all negative influences. 


\section{References}

Awoniy, Adedeji (1997). The International year of the Child (IYC) and its challenges to writers of children's books. Bendel Library Journal, 2(2), 45-49.

Beuchat, Cecilia and Valdivieso, Caroline(1992). Translation of Children's Literature: InterCultural Communication. Book Bird, 30(1), 14.

Dike, Virginia W. (1985). Children's Literature: The Nigeria situation, secondary and young adults. Nigeria Libraries, 21(2), 61-70.

Fayose, P. O. (1995) A guide to children's literature for African teachers, librarians and parents. Ibadan: AENL Educational Publishers.

Fayose, Philomena Osagee (1995). Nigerian children's literature in English. Ibadan: AENL Educational Publisher.

Kroshan, Stephen (1993). The power of reading: heights from the research. Englewood, Colorado: Libraries Unlimited.

Nkwocha, Philip U. (1972). Publishing for children in Nigeria (pp. 39-44). Benin: Ethiope Publishing Corporation.

Panandiker, Surekha (1992). Children's literature in India and its problems. Bookbird, $30(1), 4-6$.

Randall, Isobel (1992). Local literature for children in South Africa: let's give them books. Bookbird, 30(2), 5-8. 